This is a self-archived - parallel published version of this article in the publication archive of the University of Vaasa. It might differ from the original.

\title{
On the Product Development Times in various Market Properties
}

Author(s): Al Kindi, Mahmood; Summad, Emad; Shamsuzzoha, Ahm

Title: On the Product Development Times in various Market Properties

Year: $\quad 2019$

Version: Accepted manuscript

Copyright (C) 2019 IEEE. Personal use of this material is permitted. Permission from IEEE must be obtained for all other uses, in any current or future media, including reprinting/republishing this material for advertising or promotional purposes, creating new collective works, for resale or redistribution to servers or lists, or reuse of any copyrighted component of this work in other works.

Please cite the original version:

Al Kindi, M., Summad, E. \& Shamsuzzoha, A. (2019). On the Product Development Times in various Market Properties. 8th International Conference on Modeling Simulation and Applied Optimization (ICMSAO): Manama; Bahrain; 15 April 2019 through 17 April 2019. https://doi.org/10.1109/ICMSAO.2019.8880329 


\section{On the Product Development Times in various Market Properties.}

\author{
Mahmood Al Kindi* \\ Department of Mechanical and \\ Industrial Engineering \\ Muscat, Oman \\ kindim@squ.edu.om
}

\author{
Emad Summad \\ Department of Mechanical and \\ Industrial Engineering \\ Muscat, Oman \\ esummad@squ.edu.om
}

\author{
Ahm Shamsuzzoha \\ School of Technology and Innovations, \\ University of Vaasa, \\ Finland \\ ahsh@uva.fi
}

\begin{abstract}
In this paper we present a decision analytic to analyze different product development scenarios and obtain the optimal recommendation on the product development time. These scenarios differ in many aspects such as the product complexity level, the competitor's quality level, price demandsensitivity. The objective to generate managerial insights on how much time should a company spent in the development when theses market characteristics differ. In general, product development time is sensitive to this market and yet the optimal strategy varies.
\end{abstract}

\section{Keywords-Decision Analysis, Product Development}

\section{INTRODUCTION}

Current aggressive market competition demands companies selling similar products to exploit the four elements of the product marketing mix, namely Product, Price, Promotion and Place. However, for any company the problem of choosing the right product characteristics (e.g. quality, price, etc.) to increase the number of satisfied customers is a complex one. For instance, product quality and price depend on time-to-market, which is indeed a critical component where products outdate quickly. However, shortening time-to-market by skipping steps of the development process, would compromise the product quality. Hence, too fast and too slow time-to-market would affect a company's market share. Therefore, in order to acquire a decent market share companies would be looking at creating satisfied customers with positive quality perceptions. .Company's commitment to manufacturing function and organizational culture is the most important contributor to reducing development time of high quality products introduced at the right place and at the right time, which would then contribute directly to the expansion of its market share. Therefore, a company has to decide on how much time to spend on the product development process given that total time is the summation of development time and the time at market. Such a complex decision process which would determine the price (markup of development cost), the product performance is further discussed later.
The objective of this research work is to provide a managerial insight tool on how much time should be spent on product development in order to maximize profit given different market segmentations with varied prices, demand sensitivity with the price, and competing products quality.

The results of 200 thousand logit model scenario runs on optimal decision for development time and product quality revealed a number of interesting managerial insights to support the product development decisions. It was found that spending longer time on development process is recommended where development cost is relatively low compared to the price, competitor's quality improves, and/or market is less sensitive to the price while development cost is low. However, a shorter time is recommended where competitors have low quality product and it takes a company shorter time to achieve a superior quality. Intuitively, company should spend less time on development process as the market becomes more sensitive to the price or the cost for development is high.

Furthermore, it is recommended to introduce superior quality products when competitors has low quality products but only when time on development process to achieve superior quality is short. Otherwise, low to average quality is recommended in the scenarios where the time to achieve superior or $100 \%$ quality is long.

\section{LIETERARURE REVIEW}

Today's aggressive market competition demands for low price, high quality and a longer market window [1] [2]. The successful companies are able to faster introduction their products in the market efficiently with high quality. Researchers therefore emphasized to integrate marketing with product manufacturing process [3][4] [5]. The product manufacturing process is consisted of several accompanied processes such as design and development, manufacturing and selling for necessary profit [6]. The product manufacturing process involves with uncertainties due to market demand, which integrates with price and quality. The price and quality of the product also depends on the speed of time-to-market and its accompanied quality. 
Shorter product development lead-time is nowadays essential for company, which wishes to pertinent in competition or ahead of their competitors respectively. This shorter lead-time directly influences the product's introduction to the market or time-to-market. The time-tomarket is considered as the critical component in the new product design and development process [7] [8]. (MorenoMoya and Munuera-Aleman, 2016; Stock et al., 2018). This philosophy is especially important due to the shrinkage of product life cycle. In order to achieve required benefits from market share companies are looking forward to get early into the market with their new product before there is any competition [9] [10]. Such early introduction to the market offers the companies also charge premium price and to be profitable. On the other hand, late introduction to the market increase the chance that the product is already outdated causes huge financial loss to the companies. Due to the globalization of competition, companies are forced to faster time to market and cheaper development cycle times [11]. To reduce time-to-market companies need to promote organizational integration and stress the importance of design for manufacture. The commitment of manufacturing function and organizational culture is identified as the most important variable in reducing development time of new products [12]. Faster product introduction to the market enables firms to exploit the 'market window' and to secure a larger market share with enhanced price premium and extended sales life. This phenomenon offers a price premium before other competitors enter the market [13][14]. If a company able to reduce its product development lead-time through redefining its design strategy, it allows the company to start later with the advantage to incorporate the latest features and technologies in the product. Reduced time-to-market offers the opportunity for more product launches and better market intelligence and response from potential customers .

\section{Decision AnAlytic Model}

Consider a product development process where the company competes with the dominant competitor. The product demand is a function of price, quality, and time-duration in the market. The product consists of various core and non-core components shape the performance. The early launching of the product may result in less performance, cheaper product, but longer time in the market. On the other hand, the late launching may have an outstanding performance, an expensive product, but short time in the market. These conflicting objectives need to be optimized and balanced. Therefore, we develop a mathematical model that can give managerial insights to the company where the decision variables are the development time and product quality.

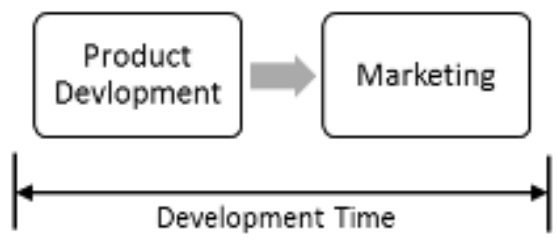

Fig 1. Product Development Process

Therefore, the company has to decide how much time to spend in the development process given that total time is the summation of development time and the time in market (Fig. 1). This decision will determine the price (markup of development cost (C)).

Profit $=$ D.P $-C$

Demand $(D)$ is assumed to have a nonlinear curve with price $(P)$, which is more general than the Linear Demand Model. The demand model presented in the paper means that each customer will buy a product either from the firm or from the competitor. The price regulates the number of customers of the total population that potentially can afford to buy the product in that price zone. The probability that a random customer entering this price zone will buy the firm's product is provided by means of discrete choice theory.

The number of customers $D_{P_{l}}$ who are willing to pay at least $P_{l}$ out of the total market size $N$

$D\left(P_{l}\right)=N\left(1-P^{\eta}\right) ; \quad \eta>0$

Where $l$ is the set of potential prices (i.e., $l=\{1,2 \ldots f\}$ ) and $\eta$ is price-demand sensitivity parameter. This parameter can be estimated from historical data or marketing surveys. Therefore, the portion of customers who are willing to pay $P_{i}$ but not $P_{i+1}$ (i.e. the next higher price) will be

$R D_{i}=D\left(P_{i}\right)-D\left(P_{i+1}\right)$

The difference between the two prices' circular areas represents residual demand [8]. Note that each donut shape represents the number of customers that are willing to pay that price out of the total population (market size).In many cases there are several competitors that sell the same product at the same price set by the firm. However, the firm's market share is determined by its performance (Fig. 2).

Profit is the clear economic objective that measures the success or failure of Six Sigma. The following assumption will be applied throughout the paper.

The firm competes with its dominant competitor.It has full awareness of that competitor's price, $P_{c}$, and performance, $Q_{c}$. 


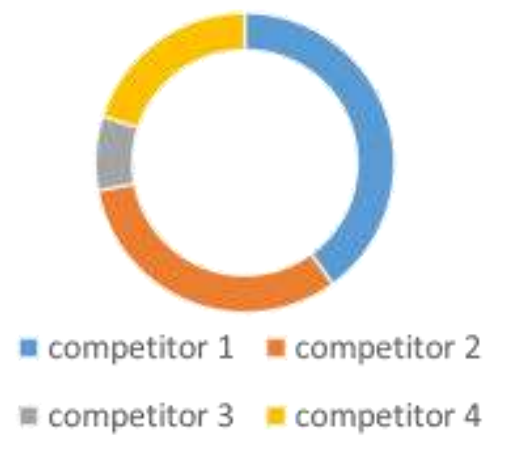

Fig 2. Market Share at given Price Pi

The customers have a logarithmic value over performance.

Following the above assumption, the market share $\mathrm{M}$ at a price $P_{i}$ and a quality $Q_{i}$ is given as

$M=R D_{i} \frac{e^{U(Q i)}}{e^{U(Q i)}+e^{U(Q c)}}$

The logit model assumes that customer value is the sum of two components: observable and non-observable attributes. The deterministic component is servable by $U\left(Q_{o}\right)$ and is a monotonic function of product performance. The random part is assumed to have a double exponential distribution function. The probability that a random customer that is willing to pay $P$ to purchase the firm's product is simply the probability that the product will give the highest value to that customer. Assume that the customer has a logarithmic value function.

$$
U(Q(.))=\ln (Q(.))
$$

Assume that the performance achieved is a linear production function of the time spent in the development. The total performance will be achieved when the team spends the total duration which obtained as

\section{Estimated Total Devlopment time $=A^{*} P C^{*} D^{\alpha}$}

Thus, the performance is assumed a linear production of time spent in the development. $\max \mathrm{M}\left(P-c_{\text {manufacturing }}\right)\left(1-P^{\eta}\right)\left(T-t_{\text {devlop }}\right) \frac{Q}{Q+Q_{c}}-\dot{C} t_{\text {devlop }}$

$Q=\frac{t_{d}}{A^{*} P C^{*} D^{\alpha}}$

$T$ : Total prduct lifecycle time

$\mathrm{t}_{\text {devlop }}:$ Total devlop- time "DecisionVar"

$Q$ : product performance

$\mathrm{Q}_{c}$ : Compititator performce

A: Constant based on past projects (size of the company)

PC:Product complexity

D: Project Diffculty

$\alpha$ : Shape parameter based on historical data.

From which we can drive

The Optimal devlopment time $t_{\text {devlop }}=-A D^{\alpha} \mathrm{PC}+$

$\frac{\sqrt{A^{2} D^{2 \alpha}(c-P)\left(-1+P^{\eta}\right)\left(-c+C+P+(c-P) P^{\eta}\right) \mathrm{PC}^{2} \mathrm{Qc}(M+\mathrm{Qc})}}{-c+C+P+(c-P) P^{\eta}}$

\section{MANAGERIAL INSIGHTS}

The objective is to provide managerial insights to the company given different market properties. These market properties varies in price, demand sensitivity with the price, and competing products quality. Moreover, there are also different product development processes such as development cost per time and actual minimum time to have a superior or $100 \%$ quality achievement in your product. The company would like to make decision on how much time should they spend such that they maximize their profit given different market segmentations. We run 200 thousand scenarios to generalize the decision on product quality and the development time. The results of the optimal solutions on product quality and development reveals interesting managerial insights to support the product development decisions. It is recommended to spend highest amount of time in the development process when the development cost is relatively low compared to the price. However, as the cost for development decrease, then less or even minimum time should be spent (Fig. 3) 


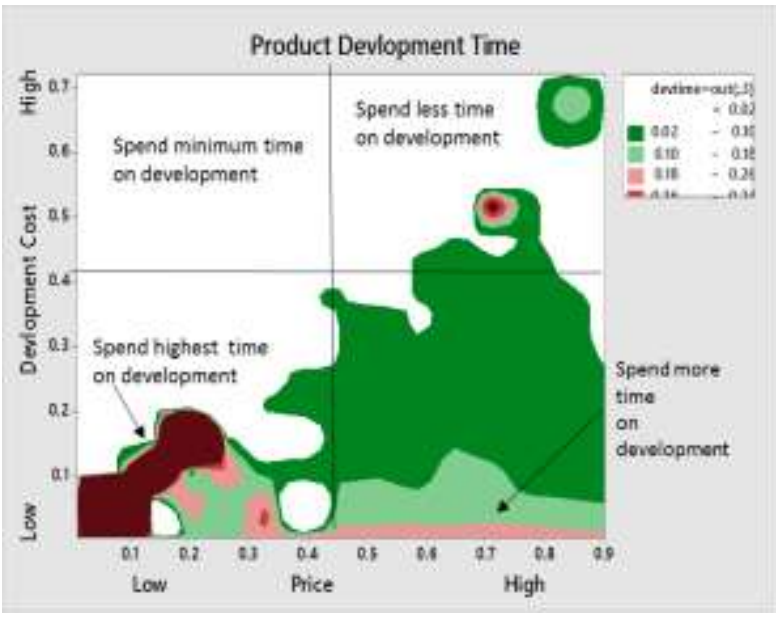

Fig 3 Product Development time in four different price segment- development cost.

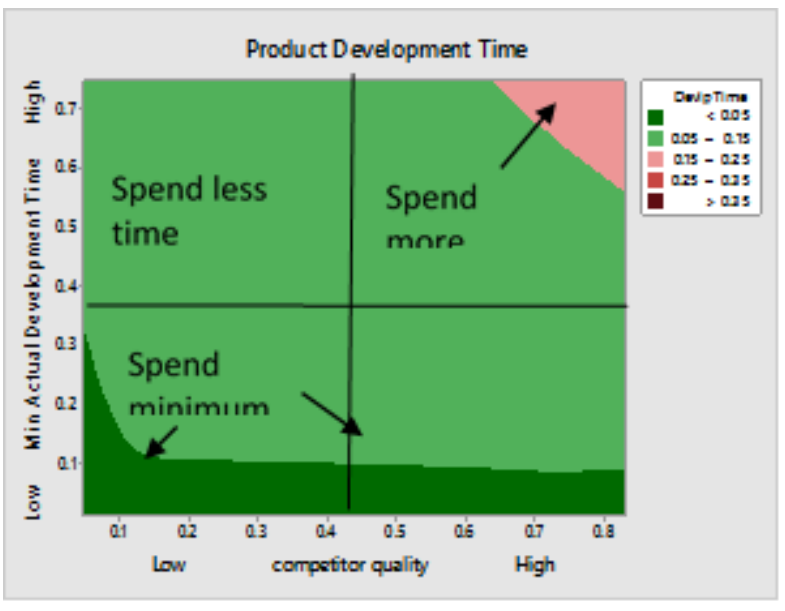

Fig 4. Product Development time in four different quality segment- development time

Fig. 4 suggests that the company spend short duration the deployment when the competitor has a low quality product and it takes the company short time to achieve superior quality. The company should spend long duration in the development as the competitor quality improves. In addition , the company should spend more time on development when the market is less sensitive to the price when the development cost is low. Intuitively, the company should spend less duration as the market becomes more sensitive to the price or the cost for development is high Fig. 5. In Fig. 6, it is always recommended to introduce superior quality product the competitor has a low quality product but only when the duration to achieve superior quality is short. Otherwise, low to average quality is recommended in the scenarios where the time to achieve superior or $100 \%$ quality is long.

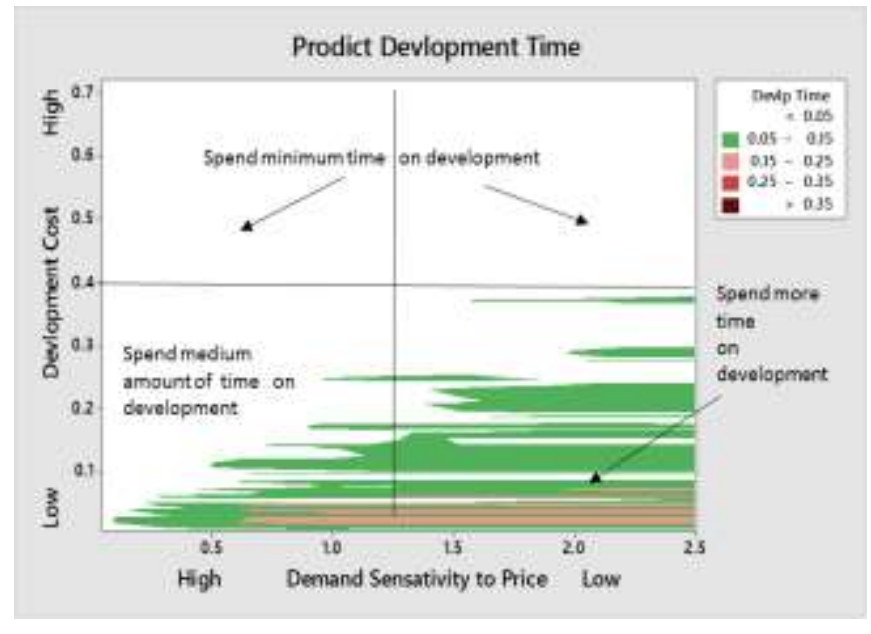

Fig 5 Product Development time in four different demand segment- development cost

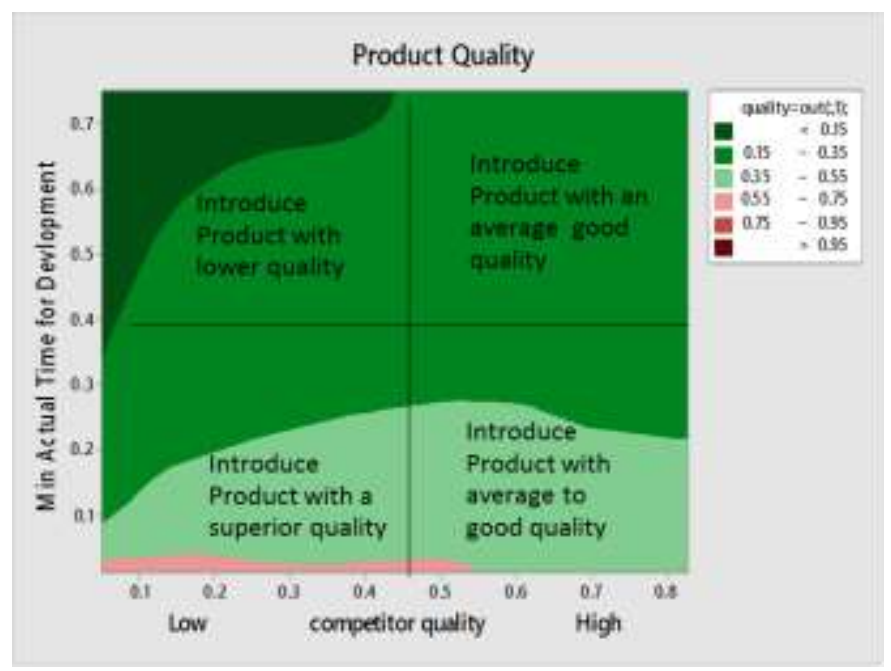

Fig 6. Optimal quality policy for four-competitor quality - time to achieve superior quality.

Product development process can be characterized by two factors: cost and duration. There are process that has a huge development cost and duration such as pharmaceutical products. Others that are low in cost and duration like mobile apps industries. Generally, as the cost for development is high then less time is spent on the development.

\section{CONCLUSION}

We present a decision analytic model to generalize the product development process time in various market properties. These characteristics varies in price demand sensitivity, competitor quality level, development cost, and product complexity. Product complexity was measured, as the actual time to achieve an outstanding quality, i.e. complex product needs more time to receive $100 \%$ quality. The optimal strategy on the how much time spent on development varies as the market conditions change. For example, it is recommended to introduce cheaper product with low quality level when the actual development time is high and 
competitor has a low quality product. Moreover, it is better to introduce best quality product when the product is not complex. The managerial insights was summarized in the figures.

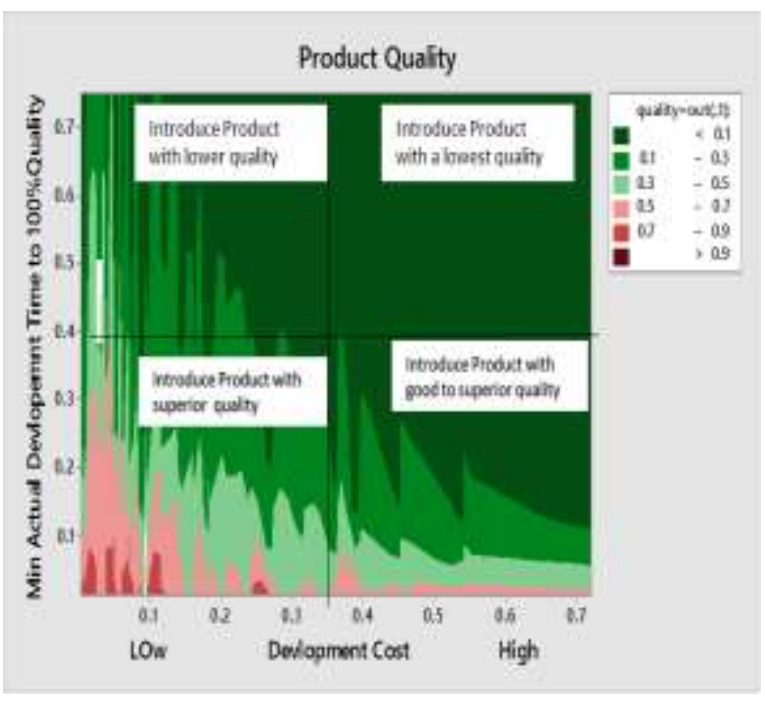

Fig 7 Optimal quality policy for four-product development process.

\section{REFERENCES}

[1]. Al Kindi, M. (2012), "Joint manufacturing and marketing decision analytic model", in Lim, G. and Herrmann, J.W. (Eds.), Proceedings of IIE Annual Conference.

[2]. Al Kindi, M. (2011). Normative approach to Six Sigma project selection. In Systems Conference (SysCon), 2011 IEEE International (pp. 189-193).

[3]. Hausman, W.H. (2002), "Why should marketing and manufacturing work together? Some exploratory empirical results", Journal of Operations Management, Vol 20. No. 3 pp. 241257.

[4]. Song, M. (2009), "Marketing-manufacturing integration across stages of new product development: Effects on the success of high- and low-innovativeness products", IEEE transactions on engineering management, Vol 56, No. 1, pp. 3144.

[5]. Paiva, E. L. (2010), "Manufacturing and marketing integration from a cumulative capabilities perspective", International Journal of Production Economics, Vol 126. No. 2, pp 379-386.

[6]. Ulrich, K., and Eppinger, S. (2004), Product Design and Development, 3rd Edition, McGraw-Hill, Inc., New York.

[7]. Moreno-Moya, M. and Munuera-Aleman, J-L. (2016), "The differential effect of development speed and launching speed on new product performance: an analysis in SMEs", Journal of
Small Business Management, Vol. 54, No. 2, pp. 750-770.

[8]. Song, M. (2009), "Marketing-manufacturing integration across stages of new product development: Effects on the success of high- and low-innovativeness products", IEEE transactions on engineering management, Vol 56, No. 1, pp. 3144.

[9]. Bashir, H.A. and Vince Thomson, V. (2001), "Importance of time-to-market of a new product", Design Studies, Vol. 22 pp. 157-167.

[10]. Durmusoglu, S.S., Hirunyawipada, T. and McNally, R.C. (2017), "New Product Development Process Implementation in a Business-To-Business Firm: The Driving and Moderating Factors for Improved Program Performance and Time-ToMarket", Journal of Business-to-Business Marketing, Vol. 24, No. 1, pp. 35-56.

[11]. Griffin, A. and Hauser, J.R. (1995), "Integrating R\&D and marketing: a review and analysis of the literature", Journal of Product Innovation Management, Vol. 13, No. 3, pp. 191215.

[12]. Chen Z. and Li, L. (2011), -The integration of manufacturing and marketing: Impact on combinative competitive capabilities and business performance", in Proceedings of International Conference on Management Science and Engineering, Rome, Italy.

[13]. Brooks, B. and Schofield, N. (1995), "Time-to-market: time equals money - but where does it all go?", World Class Design to Manufacture, Vol. 2, No. 6, pp.4-10.

[14]. Wochner, S., Grunow, M., Staeblein, T. and Stolletz, R. (2016), "Planning for ramp-ups and new product introductions in the automotive industry: Extending sales and operations planning", International Journal of Production Economics, Vol. 182, pp. 372-383. 